\title{
Histórias da formação e de professores que ensinam Matemática: possíveis aproximações teórico-metodológicas
}

\section{Stories of teacher education and of teachers who teach Mathematics: possible theoretical-methodological approximations}

\author{
Adair Mendes Nacarato ${ }^{1}$ \\ Andréia Maria Pereira de Oliveira ${ }^{2}$
}

Déa Nunes Fernandes ${ }^{3}$

\section{Resumo}

Este texto é subproduto do projeto "Mapeamento da pesquisa acadêmica brasileira sobre o professor que ensina Matemática: período 2001-2012". Dois dos focos temáticos identificados no mapeamento são tratados neste estudo: "História da formação do professor que ensina Matemática" e "História do professor que ensina Matemática". O estudo, cujo corpus reúne 45 pesquisas, buscou identificar as abordagens metodológicas e os referenciais teóricos utilizados e constatar se as pesquisas que focam nas histórias de professores que ensinam Matemática se aproximam dos estudos biográficos. A análise desses dois focos revelou que a aproximação entre eles vai além da questão metodológica: ambos são perpassados pelas vozes do sujeito professor e por seu protagonismo na construção da história da Educação Matemática e da sua própria formação, como constituinte da identidade profissional.

Palavras-chave: história da formação; história de professores; história oral; narrativas.

\begin{abstract}
This text is a sub-product of the project entitled "Mapping Brazilian academic research on the teacher who teaches Mathematics: 2001-2012 period". Two of the thematic focuses identified in the mapping are dealt with in this study: "History of the teacher training that teaches Mathematics" and "History of the teacher teaching Mathematics". The study, whose corpus brings together 45 researches, sought to identify the methodological approaches and the theoretical references used and to verify if the researches that focus on the histories of teachers who teach Mathematics are close to the biographical studies. The analysis of these two focuses revealed that the approach between them goes beyond the methodological question: both are permeated by the voices of the teacher subject and their protagonism in the construction of the history of mathematics education and its own formation, as a constituent of the professional identity.
\end{abstract}

Keywords: teacher education history; history of teachers; oral history; narratives.

\footnotetext{
${ }^{1}$ Doutora em Educação pela Universidade Estadual de Campinas. Professora da Universidade São Francisco, Brasil. Email: adamn@terra.com.br

2 Doutora em Ensino, Filosofia e História das Ciências pela Universidade Federal da Bahia e Universidade Estadual de Feira de Santana. Professora da Universidade Federal da Bahia, Brasil. Email: ampo@ufba.br

${ }^{3}$ Doutora em Educação Matemática pela Universidade Estadual Paulista “Júlio de Mesquita Filho". Professora do Instituto Federal de Educação, Ciência e Tecnologia do Maranhão, Brasil. Email: dea.fernandes@ifma.edu.br.
} 


\section{Introdução}

O presente estudo decorre de um projeto mais amplo, intitulado "Mapeamento da pesquisa acadêmica brasileira sobre o professor que ensina Matemática: período 2001 2012” (CNPq/ Processo 486505/2013-8), coordenado pelo Grupo de Estudos e Pesquisas sobre a Formação de Professores que Ensinam Matemática (GEPFPM). Esse projeto teve por objetivo mapear, descrever e sistematizar as pesquisas brasileiras que têm como foco de estudo o professor que ensina Matemática (PEM), produzidas no período de 2001 a 2012, em Programas de Pós-Graduação Stricto Sensu das áreas de Educação e Ensino da Coordenação de Aperfeiçoamento de Pessoal de Nível Superior (Capes).

Dentre os múltiplos focos temáticos identificados nesse mapeamento, dois deles nos interessaram diretamente, em decorrência de nossa própria prática de investigação: "História da formação do professor que ensina Matemática" e "História do professor que ensina Matemática". Embora possa haver uma interface entre eles, entendemos tratar-se de focos distintos.

No caso da história da formação do professor, há grupos consolidados no Brasil que vêm se dedicando ao mapeamento de instituições ou espaços institucionalizados que, em diferentes períodos históricos, se dedicaram, principalmente, à formação do professor que ensina Matemática. Dentre esses grupos, destaca-se o "Grupo História Oral e Educação Matemática" - GHOEM ${ }^{4}$, constituído em 2002, vinculado à Universidade Estadual Paulista "Júlio de Mesquita Filho" (Unesp), campus Bauru, e que agrega pesquisadores em Educação Matemática de instituições de ensino superior de diferentes regiões do País. O grupo tem desenvolvido projetos como o intitulado "Mapeamento da Formação e Atuação de Professores de Matemática no Brasil”, em um amplo espectro que alia história oral, historiografia e práticas de formação e atuação de professores que ensinam Matemática. Assim, vinculadas a esse projeto já foram desenvolvidas várias pesquisas abordando diferentes temas, períodos e modalidades de formação e atuação em diversas regiões do País. Essas investigações apresentam especificidades, considerando as realidades socioculturais e políticas, e trazem nas narrativas uma pluralidade de subtemas tomados pelo grupo como constituintes de uma história da formação de professores que ensinam Matemática no Brasil.

\footnotetext{
${ }^{4}$ Trabalhos disponíveis em www.ghoem.org.

Zetetiké, Campinas, SP, v.25, n1, jan./abr.2017, p.46-74
} 
No caso dos estudos que focalizam histórias de professores, entendemos que o foco seja o professor: sua trajetória estudantil ou profissional e a constituição de sua identidade profissional. Os modos de produção de pesquisas nesse campo têm envolvido: histórias de vida, método biográfico, autobiografias, narrativas de vida, entrevistas narrativas, memoriais de formação, dentre outros. Esses modos definem não apenas os procedimentos metodológicos de produção e de análise dos dados, como também o próprio campo teórico de referência.

Partimos do pressuposto de que possíveis interfaces entre esses dois focos possam estar em procedimentos metodológicos, como a história oral, ou no próprio processo de constituição identitária do professor a partir do seu contexto de formação. A identidade do professor apresenta marcas das trajetórias vividas e, por isso, não pode ser dissociada de sua história de formação e das instituições ou dos formadores com os quais ele conviveu. Assim, decidimos tomar esses dois focos como objeto de análise, na perspectiva de averiguar possíveis aproximações entre as investigações sobre histórias da formação docente e aquelas sobre histórias de professores que ensinam Matemática - e, mais especificamente, identificar nas pesquisas as abordagens metodológicas utilizadas, os referenciais teóricos norteadores e reconhecer se as pesquisas que focam nas histórias de professores que ensinam Matemática se aproximam dos estudos biográficos.

Para a constituição do corpus da pesquisa, utilizamos os textos produzidos pelas diferentes regionais participantes do projeto $^{5}$ e que compõem o $e$-book $k^{6}$ relativo à pesquisa nacional (Fiorentini, Passos, \& Lima, 2016), em que selecionamos os trabalhos classificados nesses dois eixos. De posse deles, procedemos à leitura dos formulários ${ }^{7}$ de mapeamento dos

\footnotetext{
${ }^{5}$ Considerando a dimensão continental do País e o volume de trabalhos produzidos nos diferentes programas de pós-graduação nas áreas de Educação e Ensino, a organização do corpus do projeto foi dividida pelas seguintes regiões/estados: São Paulo, Minas Gerais, Rio de Janeiro e Espírito Santo, Região Norte, Região Nordeste, Região Centro-Oeste e Região Sul. A Região Sudeste foi subdividida, considerando que nela está o maior número de programas de pós-graduação e, portanto, a maior produção de dissertações e teses.

${ }^{6}$ Disponivel em: www.fe.unicamp.br/biblioteca/produtos

${ }^{7}$ Este formulário possibilitou o fichamento de cada trabalho que pertencia ao corpus da pesquisa. Ele era composto dos seguintes elementos: dados identificadores da pesquisa; problemática, objetivos e questão investigativa; procedimentos metodológicos (tipo de pesquisa, processo de produção de dados, contexto e sujeitos, material ou corpus de análise, procedimentos de análise); resultados e conclusões relativos ao PEM; principais referenciais teóricos relativos ao PEM e sua presença na análise e na produção de resultados e conclusões. Um modelo desse formulário encontra-se em Fiorentini, Passos e Lima (2016).
} 
DOI: http://dx.doi.org/10.20396/zet.v25il.8647745

estudos e, em alguns casos, recorremos ao próprio texto da dissertação ou tese para nos certificarmos da sua inserção. Além disso, localizamos outras pesquisas que também se inserem no corpus de nossa análise, mas que haviam sido classificadas em outros focos nos formulários ou nos textos das regionais. Após essa conferência, algumas delas foram excluídas, outras incluídas, e totalizamos com 45, das quais 17 se referem a "Histórias da formação de professores que ensinam Matemática" e 28 se vinculam ao eixo "Histórias de professores que ensinam Matemática”. Não descartamos a possibilidade de que existam trabalhos que, embora atendam aos critérios por nós adotados, não foram inseridos neste corpus.

Após esse mapeamento inicial, passamos a organizar e analisar esses estudos segundo os dois eixos teórico-metodológicos já explicitados. O resultado dessa tarefa apresentamos a seguir.

\section{História da formação de professores que ensinam Matemática}

A partir de uma leitura inicial dos formulários de mapeamento dos estudos sobre as histórias da formação de professores, identificamos que as narrativas constituídas mobilizam como fontes os documentos oficiais e entrevistas.

O Quadro 1 mostra a síntese dessa organização dos trabalhos.

Quadro 1 - Organização dos trabalhos por subeixos de análise

\begin{tabular}{|c|c|c|}
\hline \multirow[t]{2}{*}{ Subeixo de análise } & \multicolumn{2}{|c|}{ Autores } \\
\hline & Dissertações & Teses \\
\hline $\begin{array}{l}\text { Histórias da formação de professores constituídas } \\
\text { a partir de documentos oficiais }\end{array}$ & Braga (2012) & \\
\hline $\begin{array}{l}\text { Histórias da formação de professores constituídas } \\
\text { a partir de documentos oficiais e entrevistas. }\end{array}$ & $\begin{array}{l}\text { Ferreira (2002); Silva } \\
\text { (2003); Lima (2006); } \\
\text { Andrade (2012); } \\
\text { Ruezzene (2012); Cury } \\
\text { (2007); Tabosa (2010); } \\
\text { Rodrigues (2010) }\end{array}$ & $\begin{array}{l}\text { Ziccardi (2009); Bertani } \\
\text { (2011); Barbosa (2012); } \\
\text { Pozzobon (2012); } \\
\text { Cury (2011); Fernandes } \\
(2011) \text {; Martins- } \\
\text { Salandim (2012) }\end{array}$ \\
\hline
\end{tabular}

Fonte: Corpus das dissertações/teses analisadas

Pelo Quadro 1, observamos uma concentração maior de trabalhos nos subeixos 2. No subeixo 1, temos um único estudo, Braga (2012), que utilizou como fonte documentos 
oficiais para investigar o papel desempenhado pelo Programa de Treinamento e Aperfeiçoamento de professores de Ciências Experimentais e Matemáticas (PROTAP) na formação de professores em relação à modernização do ensino da Matemática na Bahia no contexto do Movimento da Matemática Moderna (1969-1974). Foram analisados documentos oficiais (relatórios, decretos e atas) e recortes de jornais encontrados no arquivo do Centro de Memória da Faculdade de Educação da Universidade Federal da Bahia e os depoimentos contidos nos cadernos do Instituto de Física da UFBA.

No subeixo 2, histórias da formação de professores que utilizam documentos oficiais e entrevistas, identificamos sete pesquisas nas quais as entrevistas são mobilizadas na perspectiva da história oral, aquela em que os relatos orais fixados pela escrita são concebidos como documentos históricos intencionalmente constituídos, cinco delas (Cury, 2007; Cury, 2011; Fernandes, 2011; Martins-Salandim, 2012, Morais, 2012), no contexto da formação inicial de professores, investigaram a constituição de cursos; e duas (Rodrigues, 2010; Tabosa, 2010), em outros contextos, analisaram como foram apropriadas as propostas do Movimento da Matemática Moderna.

O trabalho de mestrado de Cury (2007) contou com depoimentos de 11 professores para investigar a história da constituição dos primeiros programas de ensino superior, cuja proposta era a formação de professores de Matemática no estado de Goiás. Na pesquisa de doutorado, Cury (2011) analisou os primeiros cursos de formação de professores de Matemática no estado de Tocantins. Foram realizadas 11 entrevistas com depoentes de 3 instituições: Faculdade de Educação Ciências e Letras de Araguaína (Facila), Universidade do Tocantins (Unitins) e Universidade Federal do Tocantins (UFT). Fernandes (2011) apresentou um registro histórico do processo de formação de professores de Matemática no estado do Maranhão a partir do movimento de 3 instituições públicas de ensino superior: Universidade Federal do Maranhão (UFMA), Universidade Estadual do Maranhão (UEMA) e o então Centro Federal de Educação Tecnológica do Maranhão (Cefet). A pesquisa teve como marco inicial a implantação do primeiro curso de licenciatura em matemática da UFMA na década de 1960. A autora utilizou depoimentos de 16 entrevistados, professores e técnicos administrativos que participaram dos processos de implantação e/ou desenvolvimento dos programas maranhenses para formação docente. Martins-Salandim (2012) analisou o movimento de criação, instalação e desenvolvimento de cursos de Matemática pelo interior 
do estado de São Paulo na década de 1960. Foram realizadas 15 entrevistas com professores envolvidos nos cursos em seus primeiros anos. Morais (2012) investigou, por meio de entrevistas com 8 depoentes, a criação do mais antigo curso de licenciatura da região de Mossoró-RN no período de 1940-1974.

Os dois últimos estudos deste eixo investigaram grupos de professores, também utilizando a história oral como metodologia de pesquisa. Rodrigues (2010) explorou o processo de apropriação de propostas do Movimento da Matemática Moderna por um grupo de professores da região de Ribeirão Preto-SP nas décadas de 1960, 1970 e 1980. Para tanto, entrevistou 10 professores que ensinaram Matemática na região de Ribeirão Preto. Tabosa (2010) analisou como um grupo de professores que lecionaram no Colégio Técnico de Limeira (Cotil), vinculado à Universidade Estadual de Campinas, nos 20 primeiros anos de funcionamento, percebeu os processos de transformação da instituição e as posições tomadas em relação ao Movimento da Matemática Moderna. Foram entrevistados 5 professores que ensinaram Matemática no colégio.

Neste subeixo, os trabalhos utilizaram a metodologia da história oral, apoiando-se em autores como Antonio Bolívar Botia, Antonio Vicente Marafioti Garnica, Benedito Nunes, Jorge Larrosa, José Carlos Sebe Bom Meihy, Verena Alberti, Walter Benjamin, dentre outros. Cinco trabalhos vinculados ao Grupo História Oral e Educação Matemática (GHOEM) - Cury (2007), Cury (2011), Fernandes (2011), Martins-Salandim (2012) e Morais (2012) - e também o estudo de Rodrigues (2010) deixam explícita a opção pela análise narrativa de depoimentos.

Neste subeixo também identificamos dois estudos que focaram a formação em matemática de professores dos anos iniciais em Escolas Normais; cinco trabalhos investigaram a implantação de cursos de Licenciatura em Matemática; e dois trataram sobre cursos de formação continuada.

Ferreira (2002) fez uma pesquisa histórica sobre a formação do professor de séries iniciais do Ensino Fundamental na disciplina de Matemática, proveniente das Escolas Normais do estado do Espírito Santo, no período de 1930 a 1970. Os documentos coletados e analisados em bibliotecas e arquivos estaduais e nacionais foram: provas de estudantes, relatórios e mensagens de governos, atas de resultados finais, jornais, decretos e leis, programas de disciplina, currículos, atestados de boa conduta e fotografias. Foram Zetetiké, Campinas, SP, v.25, n1, jan./abr.2017, p.46-74 
entrevistados sete depoentes, entre ex-diretores, ex-professores e ex-estudantes de Matemática de Escolas Normais. Pozzobon (2012) investigou a formação de professores que ensinam Matemática nos anos iniciais a partir de um Curso de Formação de Professores de Nível Médio de uma escola do interior do Rio Grande do Sul nas décadas de 1960 a 2000. Os documentos analisados - atas, caderno de planejamentos, Programa Experimental de Matemática, Proposta de Estágio, apostilas de planejamento -, os questionários com quatro professores que supervisionavam os estágios e as entrevistas com oito professores que ministraram as disciplinas de Matemática e Didática da Matemática formaram o corpus de dados.

Silva (2003) analisou o processo de criação e consolidação dos cursos de Matemática da Universidade Católica de Goiás (UCG) e da Universidade Federal de Goiás (UFG). Foram realizadas entrevistas com professores, ex-professores e idealizadores dos cursos, além da análise de documentos como atas, anuários, boletins, processos, livros de registros das secretarias. Ziccardi (2009) investigou o processo de criação e legitimação do Curso de Matemática da Pontifícia Universidade Católica de São Paulo (PUC-SP), Bacharelado e Licenciatura. A autora consultou arquivos, catálogos, relatórios, diários de classe, exames, livros de atas, fichas de estudantes e documentos do Departamento de Matemática da PUCSP, bem como documentos pessoais de professores, além de realizar entrevistas com 14 professores do curso e 5 técnicos administrativos que atuaram no curso. Barbosa (2012) analisou o processo de implantação do Curso de Licenciatura em Ciências Naturais e Matemática (CCNM) no Campus Universitário de Sinop, da Universidade Federal de Mato Grosso, no período de 2006 a 2010. As entrevistas foram realizadas com 3 professores elaboradores da proposta, 4 professores implementadores 2 estudantes da primeira turma do curso. Os documentos analisados foram: Projeto Pedagógico do Curso, atas de reunião de colegiado de curso e de congregação; documentos produzidos por professores do curso; produção dos estudantes do curso. Ruezzene (2012) investigou os processos de criação, expansão e consolidação dos cursos de Licenciatura em Matemática no estado de Rondônia. Foram utilizados os documentos oficiais das instituições e depoimentos de professores, coordenadores de cursos, ex-estudantes, funcionários, dentre outros atores. Por fim, o trabalho de Bertani (2011) analisou o processo histórico da formação dos professores em Matemática no Brasil e em Portugal no período de 1941 a 1968. Para cumprir tal objetivo, a autora investigou o curso de Matemática e o curso de Didática da Faculdade de Filosofia da Zetetiké, Campinas, SP, v.25, n1, jan./abr.2017, p.46-74 
DOI: http://dx.doi.org/10.20396/zet.v25il.8647745

Bahia e da Faculdade de Letras de Lisboa, de Coimbra e do Porto. O pesquisador tomou como fontes as cadernetas com registros dos professores dos Cursos de Matemática e Didática da Bahia da Faculdade de Filosofia da Bahia, textos escritos e entrevistas com estudantes e professores, relatórios dos professores da Faculdade de Letras de Lisboa e relatórios dos futuros professores portugueses da Faculdade de Letras de Coimbra.

Lima (2006) investigou os cursos que o Grupo de Estudos do Ensino da Matemática (GEEM) desenvolveu para professores que ensinavam Matemática no Ensino Secundário durante o Movimento da Matemática Moderna no Brasil nas décadas de 1960 a 1970. Foram explorados documentos - arquivos do professor Osvaldo Sangiorgi - e entrevistas com quatro docentes que ministraram cursos no GEEM e com dois professores-alunos participantes desses cursos. Andrade (2012) analisou como um grupo de professores que ensina Matemática na rede estadual de ensino de Foz do Iguaçu-PR observou as políticas educacionais implantadas e as possíveis contribuições para seu desenvolvimento profissional, ao participar de várias modalidades de formação continuada promovidas pelo governo do Paraná no período de 2003 a 2010. Para tal objetivo, as fontes foram as propostas para educação instituídas no estado, no período em estudo, e oito entrevistas com professores participantes do grupo.

Neste subeixo, no tratamento das fontes, alguns trabalhos utilizaram análise documental e análise das narrativas (Ferreira, 2002; Ziccardi, 2009; Barbosa, 2012) e outros empregaram análise textual discursiva (Andrade, 2012; Pozzobon, 2012).

Todos os estudos classificados nos dois eixos adotaram uma abordagem qualitativa, com a utilização de diferentes fontes, para apresentar os traços históricos da formação de professores em cursos Normais e de Nível Médio, Licenciatura em Matemática e programas de formação continuada. Assim, ocorreu um exercício de reconstituição de versões históricas sobre a formação de professores que ensinam/ensinarão Matemática a partir de experiências vividas e ressignificadas pelos depoentes que participaram dos processos de implantação e desenvolvimento dos cursos e programas.

Outro aspecto a ser salientado diz respeito às duas modalidades utilizadas nos estudos analisados para a apropriação da história oral: história de vida e história oral temática. A história de vida está relacionada ao estudo das experiências de vida dos depoentes. A história 
oral temática está vinculada ao depoente e à abordagem específica de um determinado tema. É uma versão histórica, constituída a partir das experiências dos depoentes vivenciadas em certos contextos e de situações relacionadas ao tema.

Dentre os estudos, há aqueles que se apropriam da história oral, visando às operações historiográficas; é o caso, por exemplo, dos de Cury (2007), Cury (2011), Fernandes (2011), Martins-Salandim (2012) e Morais (2012).

Uma operação historiográfica é um movimento composto por um conjunto de ações que se iniciam com a opção por algumas fontes para, a partir delas, analítica e metodicamente, compor uma narrativa. Usar a história oral numa operação historiográfica implica inaugurar essa operação com as fontes produzidas a partir da oralidade e, segundo as circunstâncias, incorporar paulatinamente fontes outras que possam apoiar a criação da narrativa. Não se trata de recorrer à oralidade apenas quando as fontes escritas são insuficientes, nem de teimar em restringir-se apenas às fontes orais quando há disponíveis inúmeras fontes de outra natureza (escritas, pictóricas, arquiteturais, etc.). Trata-se de iniciar um processo a partir de uma perspectiva singular, a da narrativa de um sujeito situado, e ir aos poucos abrindo esse diálogo, incorporando escritos e informações outras, ampliando essa perspectiva não para checar (ou chegar à) verdade do sujeito, mas criar um enredo que narrador e pesquisador julguem significativo como parte do acervo de que dispõem para conhecer determinado aspecto do mundo. (Garnica, 2015, p. 42)

Na sequência, apresentamos o segundo foco do nosso estudo.

\section{Histórias de professores que ensinam Matemática}

Destacamos, inicialmente, que existe uma polissemia ou dispersão terminológica para as expressões utilizadas para se referir aos trabalhos que incluímos neste eixo. Souza (2006), por exemplo, considera que "autobiografia, biografia, relato oral, depoimento oral, história de vida, história oral de vida, história oral temática, relato oral de vida e as narrativas de formação são modalidades tipificadas da expressão polissêmica História Oral” (p. 23). Embora o foco atual das pesquisas seja nas histórias de vida, Souza (2010), ao analisar a emergência desse campo teórico, principalmente no caso brasileiro, localiza sua gênese na história oral. Daí nosso pressuposto inicial de que essa abordagem metodológica possa ser a interface entre as pesquisas aqui analisadas. No decorrer da análise buscaremos identificar tais aproximações (ou não).

Essas expressões referidas por Souza (2006), embora próximas, carregam sentidos próprios; algumas se aproximam dos estudos biográficos, outras, não. No caso das narrativas, há que distinguir as narrativas orais fixadas pela escrita como fonte de dados, constituídas a 
partir da transcrição e da textualização das entrevistas; as narrativas como metodologia (são trabalhos que se apoiam no método biográfico e tanto a produção de dados quanto a análise se pautam nessa abordagem); e a pesquisa narrativa, modalidade de pesquisa que se tornou conhecida no Brasil a partir dos trabalhos de Michael Connelly e Jean Clandinin. António Nóvoa, com o seu livro Vidas de professores, é outro autor que, no final da década de 1990, se tornou referência nessa modalidade de pesquisa. Desde essa década muitos outros autores se tornaram referência, e esse foco de investigação vem aumentando significativamente, principalmente com estudos que se ancoram no método (auto)biográfico ${ }^{8}$. Esse método surge como contraponto à sociologia positivista, na década de 1920, na Escola de Chicago, e sua introdução nas ciências da educação tem se constituído não apenas em instrumento de investigação, mas também de formação. Ao lidar com fontes biográficas, “permite que seja concedida uma atenção muito particular e um grande respeito pelos processos das pessoas que se formam: nisso reside uma das suas principais qualidades, que o distinguem, além da maior parte das outras metodologias de investigação em ciências sociais" (Finger \& Nóvoa, 2010, p.23)

Nossa opção foi por apresentar, num primeiro momento, as pesquisas, e, em seguida, tentar uma caracterização mais abrangente dessa abordagem teórico-metodológica.

Uma leitura inicial dos formulários de mapeamento dos trabalhos possibilitou a identificação de quatro subeixos: 1) histórias de vidas de professores que ensinam Matemática, as quais se aproximam dos estudos (auto)biográficos; 2) histórias de vidas de professores que ensinam Matemática, as quais tomam a história oral como metodologia de pesquisa; 3) história da Educação Matemática a partir da história de trajetórias de professores; 4) Outros, ou seja, trajetórias e/ou histórias de vida de professores sem aproximações com a história oral, com a história da Educação Matemática ou com o método (auto)biográfico. O Quadro 2 apresenta a síntese dessa organização dos trabalhos.

Quadro 2: Organização dos trabalhos por subeixos de análise

\begin{tabular}{|l|c|c|}
\hline \multicolumn{2}{|c|}{ Subeixo de análise } & \multicolumn{2}{|c|}{ Autores } \\
\cline { 2 - 3 } & Dissertações & Teses \\
\hline Histórias de vida de professores que ensinam & Costa (2005); Bucholz & Alves (2010); Paris \\
\hline
\end{tabular}

\footnotetext{
${ }^{8}$ No cenário nacional, a expressão método (auto)biográfico foi popularizada a partir do livro de Nóvoa e Finger (2010). Na literatura ele também aparece apenas como método biográfico.
} 
DOI: http://dx.doi.org/10.20396/zet.v25il.8647745

\begin{tabular}{|c|c|c|}
\hline $\begin{array}{l}\text { Matemática, as quais se aproximam dos estudos } \\
\text { (auto)biográficos }\end{array}$ & $\begin{array}{l}\text { (2007); Brito (2008); } \\
\text { Camargo (2008); Paris } \\
\text { (2009); Mesquita } \\
\text { (2011); Santos (2011); } \\
\text { Santana (2012) }\end{array}$ & (2012) \\
\hline $\begin{array}{l}\text { Histórias de vidas de professores que ensinam } \\
\text { Matemática, as quais tomam a história oral como } \\
\text { metodologia de pesquisa }\end{array}$ & $\begin{array}{l}\text { Wermuth (2005); Fillos } \\
\text { (2008); Broi (2010); } \\
\text { Beltrão (2012); Savi } \\
\text { (2012). }\end{array}$ & $\begin{array}{ll}\text { Rolkouski } & \text { (2006); } \\
\text { Pamplona } & \text { (2009); } \\
\text { Lando (2012) } & \end{array}$ \\
\hline $\begin{array}{l}\text { História da Educação Matemática a partir da } \\
\text { história de trajetórias de professores }\end{array}$ & $\begin{array}{l}\text { Paschoalin } \quad \text { (2005); } \\
\text { Soares (2008); Rabelo } \\
\text { (2010); Salvador (2012) }\end{array}$ & \\
\hline Outros & $\begin{array}{l}\text { Modesto (2002); Jardim } \\
\text { (2009); Lima (2010); } \\
\text { Silva (2012) }\end{array}$ & $\begin{array}{l}\text { Azevedo (2009); Silva } \\
\text { (2010) }\end{array}$ \\
\hline
\end{tabular}

Fonte: Corpus das dissertações/teses analisadas.

Nesse quadro, é possível identificar que o maior número de trabalhos (dez, no total) insere-se no eixo 1. Três deles tomaram as narrativas como fonte de dados: Costa (2005), Santos (2011) e Mesquita (2011). São dissertações produzidas no âmbito do Mestrado Acadêmico e desenvolvidas na Universidade Federal do Pará. Costa (2005) entrevistou quatro professores com diferentes tempos de magistério, a fim de analisar seu desenvolvimento profissional. Com cada um deles, realizou duas entrevistas semiestruturadas, que ela denominou de "depoimentos dialogados", apoiando-se em Vicente Garnica. A autora reconstruiu a trajetória de formação de cada professor e optou por realizar a análise por categorias. Santos (2011) teve como foco de pesquisa a violência escolar e contou com a colaboração de professores de matemática, visando analisar suas percepções sobre a expressão "violência escolar". Para isso, ela usou a entrevista em grupo do tipo "episódica" (o foco estava delimitado na violência escolar). Contou com a colaboração de 11 professores que frequentavam um curso de formação continuada na UFPA. Os dados foram organizados em 4 categorias de análise, de acordo com as percepções manifestadas pelos professores. Em ambas as dissertações há referências aos trabalhos de Michael Connelly e Jean Clandinin sobre pesquisa narrativa. Embora não tenham realizado pesquisa narrativa, Costa (2005) e Santos (2011) tomaram a narrativa como objeto de análise. Ambas trazem 
referências a António Nóvoa, autor que também introduziu no Brasil as discussões sobre histórias de vida de professores.

Mesquita (2011) trabalhou com narrativas autobiográficas, apoiando-se em Maria Isabel Cunha, e classificou sua pesquisa como "pesquisa narrativa autobiográfica". Ele teve como aporte teórico a teoria antropológica do didático, analisando as próprias narrativas de suas lembranças sobre as praxeologias realizadas nas instituições nas quais atuou como professor de EJA e tomou a equação de $2^{\circ}$ grau como conteúdo matemático para analisar seus saberes. Ele analisa duas de suas praxeologias: a formação e a prática. Chama-nos a atenção que esta dissertação se considera como pesquisa narrativa, sem que sejam apresentados a sua característica e os princípios que a norteiam.

Bucholz (2007) também adotou as ideias de Connelly, Clandinin e Nóvoa para analisar, além de sua própria constituição docente, o processo de formação de quatro professoras gaúchas. Para isso, a pesquisadora utilizou entrevistas na forma de narrativas e transcrições dos encontros de formação. Ela realiza uma análise narrativa a partir dos fios constituintes da formação e da transformação, cruzando as vozes dessas cinco profissionais.

Fazendo uso de entrevistas narrativas, Camargo (2008) explorou os processos (auto)formativos singulares coletivos, constituintes das matrizes pedagógicas de três professores que ensinam Matemática. O trabalho fundamenta-se em investigações teóricometodológicas na abordagem (auto)biográfica. Esse foi o primeiro estudo desse subeixo que assumiu tal abordagem. A análise dos dados fundamenta-se no conceito de Matrizes Pedagógicas, na perspectiva de Ecleide Furlanetto.

A pesquisa de Alves (2010) teve como foco a própria trajetória da pesquisadora, como professora que ensina Matemática no Ensino Médio, na perspectiva de uma prática interdisciplinar. A autora caracteriza sua pesquisa como história de vida e, ao narrar a sua constituição profissional, busca vestígios teóricos que a fundamentam; realiza também análise documental, visando a qualificar sua prática.

Paris (2009), em sua dissertação, explorou a trajetória profissional do professor Ubiratan D'Ambrosio, considerando aspectos da vida pessoal, acadêmica e profissional, a partir das múltiplas ideias que ele foi construindo na Educação Matemática - as quais ela denomina de itinerários. Ela também identifica, nos estudos e nas pesquisas desse educador 
matemático, 14 princípios orientadores para a formação inicial e continuada de professores. Na tese de doutorado, Paris (2012) trabalhou com ateliês (auto)formativos com professores que ensinam Matemática. Apoiando-se na ideia de ateliês autobiográficos e baseando-se nos trabalhos de Christine Delory-Momberger, Marie-Christine Josso e Maria da Conceição Passeggi, teceu narrativamente os dados construiu a história da formação conduzida com um grupo de professores no Rio Grande do Norte, envolvidos num projeto de (auto)formação, e relatou as ações promovidas nos encontros.

Santana (2012), tomando registros reflexivos e memoriais de formação, investigou os modos como três licenciandos do curso de Ciências Naturais e Matemática, modalidade a distância, da Universidade Aberta do Brasil da Universidade Federal de Mato Grosso (UABUFMT) construíram sua identidade docente ao longo do processo de tornar-se professor. Tendo como foco a constituição identitária, a autora analisa os dados em três eixos: trajetórias de escolaridade, expectativas quanto à formação docente e a forma como os licenciandos percebem o processo de constituição de identidade docente no curso EaD/UAB.

Esses trabalhos trazem em comum o aporte de alguns autores que investigam no campo dos estudos (auto)biográficos, como: António Nóvoa, Christine Delory-Momberger, Franco Ferrarotti, Gaston Pineau, Marie-Christine Josso, Pierre Dominicé, dentre outros.

Nesse primeiro eixo ainda localizamos um trabalho que aborda histórias de vida de professores, mas a partir de outros referenciais teóricos. Trata-se do estudo de Brito (2007) que, utilizando-se da etnografia e de conversas informais, analisou a história de sua vida como professora da Educação Infantil e dos Anos Iniciais, atuando em região ribeirinha amazônica. Ela analisa como a Cultura Amazônica está representada no cotidiano imaginário das pessoas ribeirinhas. Num texto narrativo, vai construindo a história de seu percurso de professora a pesquisadora, num diálogo com autores dos estudos etnomatemáticos. Sua pesquisa não faz referências aos referenciais teóricos aqui destacados.

No eixo 2, histórias de vidas de professores que ensinam Matemática, as quais tomam a história oral como metodologia de pesquisa, identificamos oito estudos. O mais antigo deles é o de Wermuth (2005), que adota a "história oral de vida" como metodologia da pesquisa e, por meio de entrevistas, analisa os mitos que impregnam a disciplina e o professor que ensina Matemática no ensino médio. O foco da pesquisa está no imaginário e, para isso, ela explorou 
um referencial teórico próprio, entrevistando oito professores. Num entrecruzamento com as vozes dos sujeitos e dos autores de referência, ela busca identificar tais mitos.

Rolkouski (2006), em sua tese de doutorado, procurou compreender como um professor que ensina Matemática se torna o professor que é; para isso, realizou entrevistas com cinco professores de diferentes titulações. Os dados produzidos receberam múltiplos olhares: sob um enfoque sociológico, fundamentado nos trabalhos de Norbert Elias e Pierre Bourdieu; sob a perspectiva da psicologia, fundamentado nos trabalhos de Jerome Bruner; e, finalmente, uma última leitura denominada de científico-literária, em que se lê o depoimento em analogia com textos literários. Essa tese foi defendida no GHOEM.

Fillos (2008) analisou a formação e a atuação de oito professores que estudaram seus primeiros anos escolares em estabelecimentos da região de Irati-PR, no início do século XX. A autora utilizou entrevistas na perspectiva da história oral e fez análise documental. $\mathrm{O}$ trabalho possibilitou traçar um panorama da Educação Matemática na região.

Em sua dissertação, Broi (2010), usando entrevistas na perspectiva da história oral, investigou as histórias de vida de sete professores que atuavam em três cursos de graduação em Matemática no Rio Grande do Sul e foram indicados pelos estudantes como sendo bons. O pesquisador utilizou a Análise Textual Discursiva, identificando três categorias de análise: características positivas que os alunos apontam em seus professores; o que é ser professor para os sujeitos entrevistados; e a história de vida dos professores entrevistados.

Lando (2012), para analisar as práticas pedagógicas de sete professores que ensinaram Matemática do Colégio de Aplicação da Universidade Federal da Bahia (1949-1976), tomou seus depoimentos e explorou vasto material documental. Ao investigar as trajetórias profissionais dessas professoras e suas práticas, a autora vai construindo a história desse colégio e expondo as mudanças e as inovações pelas quais passou.

O trabalho de Beltrão (2012) centra-se nas trajetórias, nas vivências e nas experiências de cinco professores que ensinam Matemática no período 1960-2010. A autora utilizou entrevistas, ou, como ela denomina com base em Vicente Garnica, "depoimentos dialogados"; ela se apoiou na história oral temática, além de referir-se à pesquisa narrativa, com Michael Connelly e Jean Clandinin. Sua pesquisa visou analisar as transformações ocorridas ao longo de cinco décadas na Educação Matemática em Parintins-AM. Sua 
trajetória profissional se entrelaçou com as dos professores entrevistados, numa análise narrativa.

Ainda nesse eixo, com explicitação do uso da história oral - no caso, história oral temática -, Savi (2012) pesquisou a trajetória de formação de professores dos primeiros anos escolares do município de Jaguaruna-SC, entrevistando três professores já aposentados que estudaram no período de 1940-1960. Entrecruzando vozes das depoentes e documentos, a autora analisa a trajetória profissional dessas professoras.

Pamplona (2009) investigou a prática de professores experientes que ministram a disciplina de Estatística no curso de Licenciatura em Matemática por meio da "narrativa biográfica", no âmbito da história oral. Embora faça referências ao uso da história oral, o referencial teórico básico são as comunidades de prática de Ettienne Wenger e Jean Lave; no que diz respeito aos procedimentos de análise, o autor utilizou categorias.

Há convergência teórica nos trabalhos de Rolkouski (2006), Fillos (2008), Beltrão (2012) e Savi (2012), que se apoiam em autores que abordam a metodologia da história oral, como Alessandro Portelli, Antonio Vicente Marafioti Garnica, José Carlos Sebe Bom Meihy, Paul Thompson, dentre outros.

No eixo 3, história da Educação Matemática a partir da história de trajetórias de professores, identificamos quatro estudos. Dois deles trazem em comum o fato de terem como foco disciplinas do curso de Licenciatura. Paschoalin (2005) analisou as possíveis ressignificações manifestadas por graduandos na disciplina de Fundamentos da Metodologia do Ensino de Matemática II, da Faculdade de Educação da Unicamp. Para isso, acompanhou as aulas da professora da disciplina e analisou o material produzido pelos estudantes (cadernos de anotações de aulas, sínteses de aulas, memória estudantil dos estudantes, plano de curso e textos utilizados na disciplina). A análise centrou-se em quatro atividades que, segundo a autora, apresentaram aspectos diferenciados de problematização. Soares (2008) investigou as apropriações das práticas da Matemática Moderna na disciplina Fundamentos de Matemática Elementar numa instituição paranaense, no período 1970-1973. A autora utilizou, além de entrevistas com três professores, ex-licenciandos do curso, análise documental. Analisa as apropriações feitas pelos alunos para as práticas desenvolvidas segundo os princípios desse movimento de modernização dos currículos. 
Rabelo (2010) trabalhou com fontes orais (entrevistas) e escritas para analisar as práticas mais usuais em sala de aula de sete professores que atuaram no Lyceu de Goiânia na década de 1960. A autora constrói a história desse Lyceu e as práticas desses professores.

Salvador (2012), com base teórico-metodológica da Nova História Cultural (NHC), teve como objetivo geral levantar vestígios, na formação matemática e na prática docente da professora Estela Kaufman Fainguelernt, a fim de sinalizar o que a impulsionou a centrar sua docência e produção na área da Geometria. A partir do acervo pessoal da própria professora, o pesquisador construiu a sua trajetória profissional.

Esses trabalhos trazem em comum os referenciais teóricos, tanto no campo da história da Educação Matemática (Maria Ângela Miorim, Neuza Bertoni Pinto, Wagner Rodrigues Valente, dentre outros), como no campo da historiografia, da história cultural e da memória (Roger Chartier, Jacques Le Goff, Maurice Halbwachs, Dominique Julia, Diana Vidal, entre outros).

No último eixo, situamos seis trabalhos cujas abordagens metodológicas e teóricas não se enquadram nas três anteriores, no que diz respeito às histórias de vida, à metodologia da história oral ou à história da Educação Matemática.

O primeiro deles é de Modesto (2002), que analisou a formação continuada de professores que ensinam Matemática, visando compreender como eles/elas analisavam suas participações em cursos, seminários, workshops e outros momentos de formação. Após os professores terem respondido a um questionário, dez deles foram selecionados para realização de entrevistas. A análise foi feita na perspectiva fenomenológica por unidades de significado. A pesquisa de Azevedo (2009) com professores da Educação de Jovens e Adultos teve seu foco na dimensão afetiva (emoções e sentimentos na atuação docente). A autora utilizou entrevistas e diários dos professores e apresentou uma particularidade na análise, pois tomou os procedimentos de Amadeo Giorgi ${ }^{9}$, os quais descreveu detalhadamente na tese de doutorado.

\footnotetext{
${ }^{9}$ Amadeo Giorgi propôs um modelo empírico-compreensivo com passos bem detalhados para um trabalho fenomenológico, a saber: leitura de toda a descrição a fim de alcançar o sentido geral do todo; discriminação de unidades significativas com base em uma perspectiva psicológica e focada no fenômeno pesquisado; transformação das expressões cotidianas do sujeito em linguagem psicológica com ênfase no fenômeno investigado e síntese das unidades significativas transformadas em uma declaração consistente dos fenômenos observados em relação à experiência do sujeito (Andrade \& Holanda, 2010).
} 
Com foco no desenvolvimento profissional, Jardim (2009) analisou a trajetória profissional de professores que ensinam Matemática no Ensino Fundamental e Médio e fizeram parte do Projeto de Interiorização ofertado pela UFPA no período de 1992 a 1994. A pesquisadora realizou entrevistas com seis professores, procedendo à análise por categorias: 1) Os sujeitos da pesquisa e a sua escolha profissional: ser ou não ser, eis a questão; 2) $O$ período de formação inicial: desafios importantes na vida dos sujeitos; 3) Profissão: professor; e 4) Perspectivas de vida docente: caminhos e descaminhos da profissão.

O estudo de Silva (2010), classificado como quali-quanti, centrou-se em professores formadores em Letras e Matemática. Para analisar o perfil e a trajetória profissional desses professores, ela aplicou, inicialmente, um questionário - que analisou com software estatístico - a 62 professores desses dois cursos e, em seguida, selecionou 13 deles para uma entrevista. A análise foi desenvolvida por meio de categorias.

Lima (2010), num texto narrativo, descreve e analisa a constituição da sua profissionalidade como pedagoga e o seu papel no interior da escola pública nos movimentos de formação de professores de séries iniciais para o ensino de matemática. A autora analisa os movimentos que viveu, desde a sua entrada na escola, passando pelas transformações com seus alunos e a formação na parceria universidade-escola.

Silva (2012) analisou o perfil dos egressos do curso de Licenciatura em Matemática da Pontifícia Universidade Católica de São Paulo, relativo ao período de 2005-2010. A autora, inicialmente, enviou, via e-mail, um questionário aos egressos e, a partir do retorno e da análise preliminar, selecionou dez, dentre os que não estavam atuando na docência, para realização das entrevistas exploratórias. A análise centrou-se em categorias, visando analisar a trajetória acadêmica, o exercício da profissão e o papel do curso na escolha profissional desses egressos.

O que esses trabalhos nos apontam? Chamou-nos a atenção que, com exceção apenas do trabalho de Modesto (2002), nenhum é anterior a 2005, mesmo os que não se centram em abordagens (auto)biográficas. No que diz respeito aos estudos que se enquadram na pesquisa narrativa ou que têm como foco as narrativas, podemos dizer que esse é um campo que emergiu, no Brasil, no final dos anos 1990. Provavelmente, os trabalhos de Connelly e 
Clandinin (1995) tenham influenciado a comunidade brasileira, ao trazerem as narrativas como fonte ou como abordagem de pesquisa.

Posteriormente, em 2004, foi realizado o I Congresso Internacional de Pesquisa Autobiográfica (I CIPA) no Brasil, abrindo, dessa forma, espaços para discussões desse campo de investigação. Esse evento foi ganhando grandes dimensões em número de trabalhos produzidos, tendo a sua sétima edição ocorrido em 2016 (VII CIPA).

Há também que destacar a influência do livro organizado por António Nóvoa e Mathias Finger, cuja edição portuguesa foi traduzida no Brasil em 2010 (Nóvoa \& Finger, 2010), e que se tornou referência a muitos trabalhos que utilizam o método biográfico.

Esses eventos contribuíram para que vários educadores matemáticos passassem a trabalhar com o método (auto)biográfico e com narrativas em suas diferentes perspectivas. Os pesquisadores utilizaram, para a produção de dados, entrevistas semiestruturadas, entrevistas narrativas, escritura de memoriais ou diários. No que diz respeito aos processos analíticos, a literatura aponta dois caminhos: a análise paradigmática de dados narrativos ou a análise narrativa propriamente dita - modos esses propostos por Jerome Bruner e retomados por Bolívar, Domingo e Fernández (2001).

Segundo Bolívar, Domingo, \& Fernández (2001), a análise paradigmática de dados narrativos (narrativas, história oral ou de vida) pode ser realizada por "tipologias, taxonomias ou categorias, a fim de se chegar a determinadas generalizações do grupo estudado" (p. 107). Afirmam, ainda, que eles podem ser analisados de maneira diacrônica, pois contêm informação temporal acerca das relações sequenciais entre os acontecimentos; e pode haver também uma ordenação com relações causais - ou sincrônica -, quando os dados são entrecruzados, visando às questões de pesquisa postas pelo investigador. A teoria da investigação também está relacionada com as opções do pesquisador: ou ela é discutida a priori, e os dados ou conceitos são categorizados a partir dela; ou ela emerge dos dados. Nesse caso, a teoria fundamentada (grounded theory) tem sido utilizada, com vistas a generalizar. Os autores ainda alertam que, na modalidade paradigmática de análise - que prevaleceu na maioria dos trabalhos -, muitas vezes, as vozes dos depoentes são apenas ilustrativas dos conceitos teóricos. 
$\mathrm{Na}$ análise narrativa, as vozes dos depoentes (dados da pesquisa) e as dos autores se cruzam numa história ou trama, configurando um novo relato narrativo; essa nova narrativa dá significado aos dados produzidos. Não há a intenção de generalizar dados, mas de construir histórias particulares. Identificamos, principalmente nos trabalhos com a história oral, esse modo de apresentação da pesquisa. Além disso, nessa abordagem, observamos as aproximações metodológicas entre os estudos que tomam o método (auto)biográfico e os que tomam a história oral como modos de produção de narrativas ou histórias de vida.

Também confirmamos a polissemia dos termos utilizados nos trabalhos em Educação Matemática (Nacarato, Passos, \& Silva, 2014; Souza, 2010). No entanto, há uma convergência entre eles: a construção de histórias de professores ou grupos de professores, suas trajetórias e identidades profissionais.

Finalmente, há que ressaltar, mais uma vez, a pesquisa narrativa, também presente no corpus da análise deste trabalho. Diferentemente das abordagens anteriores com o uso de narrativas, a pesquisa narrativa pressupõe a etnografia, ou seja, a presença do pesquisador no grupo pesquisado. E, mais ainda, pressupõe também - embora ainda não se configure como um consenso - a produção de uma narrativa que entrelace as múltiplas vozes dos envolvidos: autores, depoentes e pesquisadores, num texto que produza significados para a experiência vivida.

Já apontamos aqui que o trabalho mais antigo do nosso corpus de pesquisa (Wermuth, 2005) insere-se nessa modalidade de pesquisa. E, como os demais trabalhos identificados nessa modalidade são oriundos da Universidade Federal do Pará (UFPA), vale destacar que, provavelmente, sejam decorrentes do fato de a professora Terezinha Valim Oliver Gonçalves $^{10}$, professora dessa instituição, ter realizado sua pesquisa de doutorado nessa abordagem. Há também que considerar que sua orientadora, Profa. Dra. Rosália Aragão, era, na época, professora da Faculdade de Educação da Unicamp e depois passou a compor o quadro docente da UFPA. Isso, talvez, pode ter influenciado outros pesquisadores da instituição. O trabalho de Connelly e Clandinin (1995) constitui-se em referência para essas

\footnotetext{
10 Gonçalves, T. O. V. (2000). Ensino de Ciências e Matemática e formação de professores: marcas da diferença. Tese de Doutorado em Educação, Universidade Estadual de Campinas. Campinas.
} 
DOI: http://dx.doi.org/10.20396/zet.v25il.8647745

pesquisas; provavelmente, o livro dos autores, publicado em 2011 (Clandinin \& Connelly, 2011), com edição revisada em 2015, será referência para novos pesquisadores.

Quanto à história oral, mesmo que ela seja utilizada sem o fim de uma operação historiográfica, como é o caso da pesquisa de Rolkouski (2006), por exemplo, ela estará relacionada à escrita da história, uma vez que as fontes orais intencionalmente produzidas pelo pesquisador são versões que carregam um caráter historiográfico, "por serem registros de um tempo, de um espaço, de uma série de práticas" (Garnica, 2015, p. 41).

Nosso estudo também aponta que a história oral se constitui em uma abordagem metodológica para as histórias de vida de professores. Nessa perspectiva, destacam-se também as pesquisas do GHOEM, vinculadas ao uso de análise (narrativa) de narrativas na/para a História da Educação Matemática. Pesquisas mais recentes nessa abordagem podem ser encontradas na Edição Temática do Bolema ${ }^{11}$ sobre narrativas e Educação Matemática.

Igualmente importantes são os trabalhos que abordam a história da Educação Matemática a partir das vozes daqueles que viveram no período analisado, frequentaram os cursos investigados e tiveram suas trajetórias pessoais ou profissionais construídas nesses cenários. Há, por parte dos pesquisados nesse foco de investigação, os modos peculiares de produção de pesquisas historiográficas, complementando fontes orais com escritas e se preocupando com análises não de categorias, mas de cenários históricos. Em tais pesquisas, as histórias dos sujeitos se cruzam com as histórias institucionais ou curriculares, sem perder o foco na história do professor.

O mapeamento aqui realizado também permitiu identificar outros modos de produzir pesquisas com histórias de professores. No entanto, nos pareceu não se tratar de modos consensuais. Isso, sem dúvida, requer um aprofundamento nesses estudos para buscarmos indícios de como essas trajetórias ou histórias são tratadas teórica e metodologicamente. No entanto, esse não é o foco do nosso estudo.

\section{Aproximações entre pesquisas sobre histórias da formação de professores e histórias de professores que ensinam Matemática}

${ }^{11}$ Ver v. 28, n. 49, p. 701-716, ago. 2014. 
Partimos do pressuposto de que um elemento de aproximação dos dois focos das pesquisas analisadas seria a opção pela história oral como abordagem qualitativa de pesquisa para a (re)constituição de cenários referentes às trajetórias profissionais de professores, de programas ou cursos. Esse pressuposto se confirmou, visto que os dois focos geraram pesquisas com a presença dessa metodologia: a história oral é tomada como um dos modos de produzir, intencionalmente, fontes com fins e propósitos diversos. As narrativas orais, tornadas escritas, configuram-se como fontes historiográficas. São memórias registradas que se transformam em objetos de investigação, possibilitando compreender os sentidos do que foi vivido à luz das preocupações do tempo presente. É através do trabalho da subjetividade contida nas narrativas orais que os indivíduos constroem e atribuem significado à própria experiência e à própria identidade.

As pesquisas nos dois focos trazem à cena do processo educativo o sujeito professor, dão visibilidade à sua formação e constituem seus cenários a partir da voz desse sujeito e dos relatos da experiência vivida por ele no contexto analisado. Não perdendo de vista que "ninguém pode aprender da experiência de outro, a menos que essa experiência seja de algum modo revivida e tornada própria" (Larrosa, 2002, p.27) e considerando a perspectiva em que a história oral notadamente atua, o que se analisa não é, propriamente, a experiência do outro, mas o relato dessa experiência. Só nos aproximamos da experiência a partir de mediações. A narrativa da experiência vivida é uma dessas formas de aproximação. Assim, o que se capta não é a experiência do outro, mas aspectos dessa experiência a partir do que o outro nos relata daquilo que viveu. Essa parece ser a única forma possível de tornar própria a experiência do outro.

Ou seja, a análise desses dois focos nos possibilitou identificar que a aproximação entre eles vai além da questão metodológica: as vozes do sujeito professor e o seu protagonismo na construção da história da Educação Matemática constituem o fulcro dessa proximidade. André (2011), em suas pesquisas, já apontava ser esta uma tendência das pesquisas em Educação. Ela considera que vários podem ser os motivos para pós-graduandos se interessarem em ouvir os professores, mas não há dúvida de que "queremos conhecer mais e melhor os professores e seu trabalho docente porque temos a intenção de descobrir os caminhos mais efetivos para alcançar um ensino de qualidade, que se reverta numa aprendizagem significativa para os alunos" (p. 29). 
Todas essas pesquisas, ao escutarem o professor, trazem para o centro do debate um novo construto para os processos formativos: a constituição identitária do professor. Assim, nosso segundo pressuposto também se confirma.

Igualmente preocupantes são as questões éticas das pesquisas que lidam com histórias de vida de professores. Larrosa Bondía (2014) ajuda a aliviar algumas tensões:

Nós somos os que convertemos as vidas e as palavras dos outros em saber, em conhecimento, em informação, em cultura, em mercadoria. Teríamos que problematizar constantemente nossos conceitos, nossas teorias, nossos métodos. E para essa problematização, ao que me parece, deveríamos atender às lições dos escritores, dos narradores, dos poetas. Ainda que não saibamos o que fazer com elas. Ainda que nos deixem, às vezes, perplexos, sem palavras. (p. 742)

Sem dúvida, há muitos desafios para o campo das pesquisas sobre histórias de formação e de vida, independente das abordagens metodológicas utilizadas. São pesquisas que não apenas escutam os professores, mas também buscam por sentidos e significados das experiências vividas.

Não me abandonará nunca essa sensação de que é precisamente quando não somos ninguém em particular que a experiência se dá com especial intensidade ao tempo que nos faz inapropriados em sua insignificância. Queria advogar aqui por essa ternura. Uma ternura que não está desprovida de atenção, de paciência, de respeito, de sofrimento e, às vezes, de silêncios. E que tem a ver, de forma não desenhável, com algo que, por falta de uma expressão melhor, chamarei de honestidade na linguagem, na escrita. (Larrosa Bondía, 2014, p. 743)

Esse respeito e essa honestidade de linguagem, presentes nos trabalhos aqui analisados, precisam continuar sendo a marca das pesquisas em Educação Matemática que tomam como objeto de análise as histórias de formação ou as histórias de professores.

\section{Referências}

André, M. (2011). Pesquisas sobre formação de professores: tensões e perspectivas do campo. In H. A. Fontoura, \& M. SILVA (Orgs.), Formação de professores, culturas: desafios à Pós-graduação em Educação em suas múltiplas dimensões In E-book online, 10 Encontro de Pesquisa em Educação da Região Sudeste. Rio de Janeiro: Anped Sudeste, 2011. Retirado em 20 de setembro de 2016, de http://www.fe.ufrj.br/anpedinha2011/sobre.html, p.24-36.

Andrade, C. C., \& Holanda, A. F. (2010). Apontamentos sobre pesquisa qualitativa e pesquisa empírico-fenomenológica. Estudos de Psicologia, 27(2), 259-268. 
DOI: http://dx.doi.org/10.20396/zet.v25il.8647745

Bolívar, A., Domingo, J., \& Fernández, M. (2001). La investigación biográfica-narrativa em educación: enfoque y metodología. Madrid: La Muralla.

Clandinin, D. J., \& Connelly, F. M. (2011). Pesquisa narrativa: experiência e história em pesquisa qualitativa. Uberlândia: UDUFU.

Connelly, F. M., \& Clandinin, D. J. (1995) Relatos de experiencia e investigación narrativa. In J. Larrosa, R. Arnaus, V. Ferrer, N. Pérez de Lara, F. M. Connelly, D. J. Clandinin, \& M. Greene, Déjame que te cuente: ensayos sobre narrativa y educación (pp.11-59). Barcelona: Laertes.

Finger, M.; Nóvoa, A. (2010). Introdução. In Nóvoa, A., \& Finger, M. (Org.). O método (auto)biográfico e a formação. Natal: EDUFRN; São Paulo: Paulus, p. 19-29.

Fiorentini, D., Passos, C. L. B., \& Lima, R. C. R. (Orgs.). (2016). Mapeamento da pesquisa acadêmica brasileira sobre o professor que ensina Matemática: período 2001-2012. Campinas: FE-Unicamp. E-book.

Garnica, A. V. M. (2015). História oral em educação matemática: um panorama sobre pressupostos e exercícios de pesquisa. História Oral, 18(2), 35-53.

Larrosa, J. (2002, janeiro/fevereiro/março/abril). Notas sobre a experiência e o saber de experiência. Revista Brasileira de Educação, 19, 20-28.

Larrosa Bondía, J. (2014, agosto). 20 minutos na fila: sobre experiência, relato e subjetividade em Imre Kertész (Filipe Santos Fernandes, Trad.). Boletim de Educação Matemática-BOLEMA, 28(49), 717-743.

Nacarato, A. M., Passos, C. L. B., \& Silva, H. (2014). Narrativas na pesquisa em Educação Matemática: caleidoscópio teórico e metodológico. Boletim de Educação Matemática BOLEMA, 28(49), 701-716.

Nóvoa, A. (1992). Vidas de professores. Portugal: Porto.

Nóvoa, A., \& Finger, M. (Org.). (2010). O método (auto)biográfico e a formação. Natal: EDUFRN; São Paulo: Paulus.

Souza, E. C. (2006). A arte de contar e trocar experiências: reflexões teórico-metodológicas sobre história de vida em formação. Revista Educação em Questão, 25(11), 22-39. 
DOI: http://dx.doi.org/10.20396/zet.v25i1.8647745

Souza, E.C. (2010, julho/dezembro). Pesquisa narrativa, (auto)biografias e história oral: ensino, pesquisa e formação em Educação Matemática. Ciências Humanas e Sociais em Revista, 32(2) 13-27.

\section{APÊNDICE 1: Relação das teses e dissertações do corpus de análise deste estudo}

Alves, A. (2010). Contribuições de uma prática docente interdisciplinar à Matemática do Ensino Médio. Tese de Doutorado em Educação: Currículo. São Paulo: Pontifícia Universidade Católica de São Paulo.

Andrade, S. V. R. de. (2012). As políticas educacionais do estado do Paraná no período de 2003 a 2010 e o desenvolvimento profissional dos professores de matemática. Dissertação de Mestrado em Educação para a Ciência e a Matemática. Maringá: Universidade Estadual de Maringá.

Azevedo, V. L. A. (2009). Emoções e sentimentos na atuação docente: um estudo com professores de Matemática na Educação de Jovens e Adultos. Tese de Doutorado em Psicologia da Educação. São Paulo: Pontifícia Universidade Católica de São Paulo.

Beltrão, I. do S. L. (2012). Vivências e experiências em educação matemática no município de Parintins/AM. Dissertação de Mestrado em Educação em Ciências na Amazônia, Parintins: Universidade do Estado do Amazonas.

Barbosa, E. P. (2012). Leituras sobre processo de implantação de uma Licenciatura em Ciências Naturais e Matemática por área do conhecimento. Tese de Doutorado em Educação Matemática. Rio Claro: Universidade Estadual Paulista "Júlio de Mesquita Filho".

Bertani, J. A. (2011). Formação de professores de Matemática: um estudo comparativo entre a Bahia e Portugal (1941-1968). Tese de Doutorado em Ensino, Filosofia e História das Ciências. Salvador: Universidade Federal da Bahia/ Universidade Estadual de Feira de Santana. 
DOI: http://dx.doi.org/10.20396/zet.v25il.8647745

Braga, M. N. S. (2012). O programa de treinamento e aperfeiçoamento de professores de ciências experimentais e matemática - PROTAP (1969-1974): sua contribuição para a modernização do ensino de matemática. Dissertação de Mestrado em Ensino, Filosofia e História das Ciências. Salvador: Universidade Federal da Bahia/ Universidade Estadual de Feira de Santana.

Brito, M. A. R. de B. (2007). Educação matemática, cultura amazônica e prática pedagógica: à margem de um rio. Dissertação de Mestrado em Educação em Ciências e Matemáticas. Belém: Universidade Federal do Pará.

Broi, M. P. da. (2010). Professores de matemática: trajetória docente e história de vida entrelaçadas. Dissertação de Mestrado em Educação em Ciências e Matemática, Porto Alegre: Pontifícia Universidade Católica do Rio Grande do Sul.

Bucholz, S. D. (2007). Conversas ao pé do ouvido: histórias de professoras que ousam fazer diferente. Dissertação de Mestrado em Ensino de Ciências. Ijuí: Universidade Regional do Noroeste do Rio Grande do Sul.

Camargo, M. C. B. (2008). As matrizes pedagógicas dos professores de Matemática: contribuições aos estudos (auto)biográficos. Dissertação de Mestrado em Educação, São Paulo: Universidade Cidade de São Paulo.

Costa, R. A. B. (2005). Desenvolvimento profissional de professores de matemática em Araguaína - Tocantins: cruzando caminhos, rompendo barreiras e fazendo. Dissertação de Mestrado em Educação em Ciências e Matemáticas. Belém: Universidade Federal do Pará.

Cury, F. G. (2007). Uma narrativa sobre a formação de professores de Matemática em Goiás. Dissertação de Mestrado em Educação Matemática. Rio Claro: Universidade Estadual Paulista "Júlio de Mesquita Filho".

Cury, F. G. (2011). Uma história da formação de professores de Matemática e das instituições formadoras do estado do Tocantins. Tese de Doutorado em Educação Matemática. Rio Claro: Universidade Estadual Paulista "Júlio de Mesquita Filho".

Fernandes, D. N. (2011). Sobre a formação do professor de Matemática no Maranhão: cartas para uma cartografia possível. Tese de Doutorado em Educação Matemática. Rio Claro: Universidade Estadual Paulista "Júlio de Mesquita Filho". 
DOI: http://dx.doi.org/10.20396/zet.v25il.8647745

Ferreira, V. L. (2002). A Educação Matemática nas escolas do Espírito Santo: um resgate histórico da formação de professores. Dissertação de Mestrado em Educação. Vitória: Universidade Federal do Espírito Santo.

Fillos, L. M. (2008). A Educação Matemática em Irati (PR): memórias e história. Dissertação de Mestrado Acadêmico em Educação. Curitiba: Universidade Federal do Paraná.

Jardim, J. J. dos S. (2009). Trajetórias de formação: o desenvolvimento profissional de Professores de Matemática. Dissertação de Mestrado em Educação em Ciências e Matemáticas. Belém: Universidade Federal do Pará.

Lando, J. C. (2012). Práticas, inovações, experimentações e competências pedagógicas das professoras de matemática do Colégio de Aplicação da Universidade da Bahia (19491976). Tese de Doutorado em Ensino, Filosofia e História das Ciências. Salvador: Universidade Federal da Bahia/Universidade Estadual de Feira de Santana.

Lima, C. M. P. B. (2010). Trajetórias no chão da escola: uma pedagoga nas trilhas da Educação Matemática com professores de séries iniciais. Dissertação de Mestrado em Educação, Curitiba: Universidade Federal do Paraná.

Lima, F. R. de. (2006). GEEM-Grupo de Estudos no Ensino da Matemática e a formação de professores durante o movimento da Matemática Moderna no Brasil. Dissertação de Mestrado em Educação Matemática, São Paulo: Universidade Católica de São Paulo.

Martins-Salandim, M. E. (2012). A interiorização dos cursos de Matemática no estado de São Paulo: um exame da década de 1960. Tese de Doutorado em Educação Matemática. Rio Claro: Universidade Estadual Paulista “Júlio de Mesquita Filho”.

Mesquita, F. N. (2011) As dinâmicas praxeológicas e cognitivas e a construção do conhecimento didático do professor de matemática. Dissertação de Mestrado em Educação em Ciências e Matemáticas. Belém: Universidade Federal do Pará.

Modesto, M. A. (2002). Formação continuada de professores de Matemática: compreendendo perspectivas, buscando caminhos. Dissertação de Mestrado em Educação para a Ciência. Bauru: Universidade Estadual Paulista "Júlio de Mesquita Filho". 
DOI: http://dx.doi.org/10.20396/zet.v25il.8647745

Morais, M. B. de. (2012). Peças de uma história: formação de professores de Matemática na região de Mossoró (RN). Dissertação de Mestrado em Educação Matemática. Rio Claro: Universidade Estadual Paulista “Júlio de Mesquita Filho".

Pamplona, A. S. (2009). A formação estatística e pedagógica do professor de Matemática em comunidades de prática. Tese de Doutorado em Educação. Campinas: Universidade Estadual de Campinas.

Paris, S. L. (2009). Itinerários e marcas na formação do sujeito formador: reflexões acerca de um caminho na educação matemática. Dissertação de Mestrado em Educação. Natal: Universidade Federal do Rio Grande do Norte.

Paris, S. L. (2012). Os ateliês (auto)formativos na constituição do sujeito docente da educação matemática. Tese de Doutorado em Educação. Natal: Universidade Federal do Rio Grande do Norte.

Paschoalin, A. C. B. (2005). Memória, história e formação de professores: o caso da disciplina Fundamentos da Metodologia do Ensino de Matemática II. Dissertação de Mestrado em Educação. Campinas: Universidade Estadual de Campinas.

Pozzobon, M. C. C. (2012). Práticas de ensino de matemática: regimes e jogos de verdade na formação do professor de anos iniciais (1960-2000). Tese de Doutorado em Educação. São Leopoldo: Universidade do Vale do Rio do Sinos.

Rabelo, R. S. (2010). Quando fui professor de Matemática no Lyceu de Goiânia: um estudo sobre a prática docente na década de 1960. Dissertação de Mestrado em Educação em Ciências e Matemática, Goiânia: Universidade Federal de Goiás.

Rodrigues, Z. G. M. (2010). O movimento da Matemática moderna na região de Ribeirão Preto: uma paisagem. Tese de Doutorado em Educação. Campinas: Universidade Estadual de Campinas.

Rolkouski, E. (2006). Vida de professores de Matemática - (im)possibilidades de leitura. Tese de Doutorado em Educação Matemática. Rio Claro: Universidade Estadual Paulista "Júlio de Mesquita Filho". 
DOI: http://dx.doi.org/10.20396/zet.v25il.8647745

Ruezzene, G. B. (2012). Os cursos de Licenciatura em Matemática no estado de Rondônia: um panorama histórico. Dissertação de Mestrado em Educação. Cuiabá: Universidade Federal de Mato Grosso.

Salvador, M. F. M. (2012). Uma História de Paixão: Estela Kaufman Fainguelernt e o ensino da geometria. Dissertação de Mestrado Profissional em Educação Matemática. Vassouras: Universidade Severino Sombra.

Santana, V. F. (2012). Constituição de identidade docente em memoriais de licenciandos do curso de ciências naturais e matemática a distância da UAB-MT. Dissertação de Mestrado em Educação. Cuiabá: Universidade Federal de Mato Grosso.

Santos, P. F. (2011). Violência escolar: o ponto de vista de professores de matemática. Dissertação de Mestrado em Educação Matemática. Belém: Universidade Federal do Pará.

Savi, V. de S. F. (2012). Memórias e histórias de formação de professores(as) dos primeiros anos escolares (1940-1960) Jaguaruna - SC. Dissertação de Mestrado em Educação. Criciúma: Universidade do Extremo Sul Catarinense.

Silva, D. J. G. (2003). Os cursos superiores de Matemática da Universidade Católica de Goiás e da Universidade Federal de Goiás: história e memória. Dissertação de Mestrado em Educação. Goiânia: Universidade Católica de Goiás.

Silva, A. K. M. da. (2010). Trajetória Formativa dos Professores dos cursos de letras e matemática da Universidade do Estado do Pará (UEPA). Tese de Doutorado em Educação. Rio de Janeiro: Pontifícia Universidade Católica do Rio de Janeiro.

Silva, D. da. (2012). O curso de licenciatura em matemática da PUC/SP e a trajetória profissional de seus egressos (2005-2010). Dissertação de Mestrado em Educação Matemática. São Paulo: Pontifícia Universidade Católica de São Paulo.

Soares, E. T. P. (2008). Práticas de Apropriação da Matemática Moderna na Licenciatura. Dissertação de Mestrado Acadêmico em Educação. Curitiba: Universidade Católica do Paraná. 
DOI: http://dx.doi.org/10.20396/zet.v25i1.8647745

Tabosa, M. F. (2010). O Colégio Técnico de Limeira e o Movimento da Matemática Moderna: uma paisagem. Dissertação de Mestrado em Educação. Campinas: Universidade Estadual de Campinas.

Ziccardi, L. R. N. (2009). O curso de Matemática da Pontifícia Universidade Católica de São Paulo: uma história de sua construção/desenvolvimento/legitimação. Tese de Doutorado em Educação Matemática. São Paulo: Pontifícia Universidade Católica de São Paulo.

Wermuth, S. B. B. (2005). O imaginário na história de vida do professor de matemática. Dissertação de Mestrado em Educação. Santa Maria: Universidade Federal de Santa Maria. 